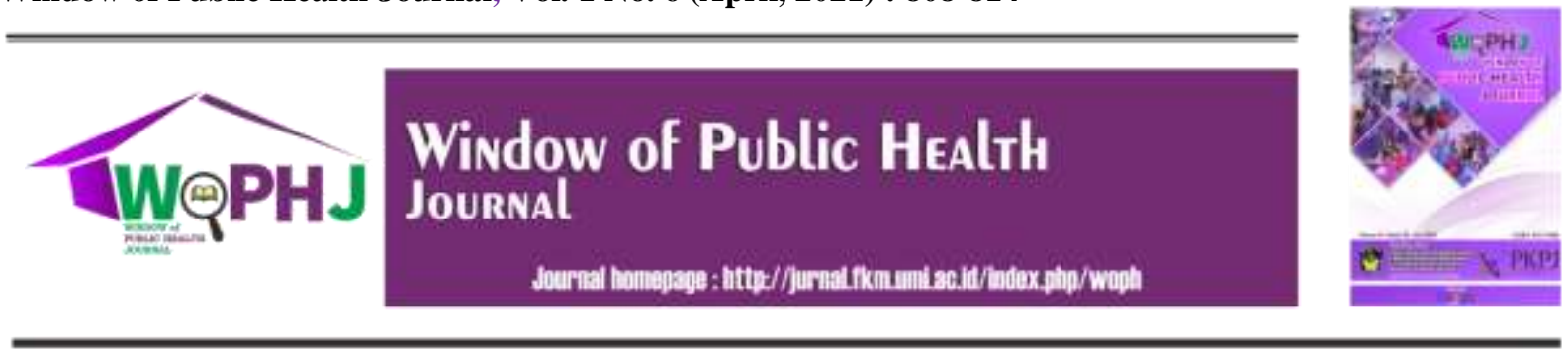

ARTIKEL RISET
URL artikel: http://jurnal.fkm.umi.ac.id/index.php/woph/article/view/woph1610

\title{
MODEL KOMUNIKASI SMCR BIDAN BERHUBUNGAN DENGAN PENGETAHUAN IBU HAMIL DALAM MENCEGAH KEMATIAN IBU
}

\author{
${ }^{\mathrm{K}}$ Suci Aprilia ${ }^{1}$, Yusriani' ${ }^{2}$, Muhammad Ikhtiar ${ }^{3}$ \\ ${ }^{1,2}$ Peminatan Promosi Kesehatan, Fakultas Kesehatan Masyarakat, Universitas Muslim Indonesia \\ ${ }^{3}$ Peminatan Kesehatan Lingkungan, Fakultas Kesehatan Masyarakat, Universitas Muslim Indonesia \\ Email Penulis Korespondensi $\left({ }^{\mathrm{K}}\right)$ : yusriani.yusriani@umi.ac.id \\ suciaprilia1304@gmail.com ${ }^{1}$, yusriani.yusriani@umi.ac.id, muhammad.ikhtiar@umi.ac.id ${ }^{3}$
} $(085255997212)$

\begin{abstract}
ABSTRAK
Angka Kematian Ibu (AKI) menjadi salah satu indikator penting dari derajat kesehatan masyarakat. Tahun 2018 rekapitulasi data kabupaten/kota menunjukkan jumlah kasus kematian ibu di kabupaten kolaka sebanyak 7 kasus. Berdasarkan data yang diperoleh di Puskesmas Kolakaasi pada tahun 2018 terjadi kasus Kematian Ibu berjumlah satu orang. Mengingat terjadinya kematian pada ibu hamil maka peningkatan komunikasi antara petugas kesehatan dengan ibu hamil harus lebih efektif.Metode penelitian ini merupakan penelitian kuantitatif. Desain penelitian yang digunakan yaitu cross sectional yang bertujuan untuk mengetahui hubungan model komunikasi SMCR bidan dengan pengetahuan ibu hamil dalam mencegah kematian ibu di Puskesmas Kolakaasi Tahun 2020. Dalam penelitian ini jumlah sampel sebanyak 93 responden dan dilaksanakan pada tanggal 25 Juni 2020 di Puskesmas Kolakaasi. Pengambilan sampel dalam penelitian ini menggunakan probability sampling dengan teknik simple random sampling. Metode analisa data menggunakan tabel distribusi frekuensi dengan uji kolerasi chi square.Setelah ditemukannya pengetahuan ibu hamil yang masih kurang alangkah baiknya jika komunikasi SMCR bidan lebih ditingkatkan lagi agar ibu hamil semakin paham dengan konsep pentingnya menjaga kesehatan ibu hamil dalam mencegah kematian ibu tersebut. Diharapkan bidan dapat mengembangkan komunikasi dalam memberikan informasi menggunakan media informasi dan menerapakan keterampilan komunikasi yang lebih efektif, dan mempertahankan sikap ibu hamil yang sudah baik dalam mencegah kematian ibu. Dari hasil penelitian dapat disimpulkan bahwa Ada hubungan antara model komunikasi SMCR bidan dengan pengetahuan ibu hamil dalam mencegah kematian ibu.
\end{abstract}

Kata Kunci : Pengetahuan; model komunikasi; bidan; angka kematian ibu.

\section{PUBLISHED BY :}

Pusat Kajian dan Pengelola Jurnal

Fakultas Kesehatan MasyarakatUMI

Address :

Jl. Urip Sumoharjo Km. 5 (Kampus II UMI)

Makassar, Sulawesi Selatan.

Email

:jurnal.woph@umi.ac.id

Phone :

+62 85395041141

\section{Article history :}

Received: 14 September 2020

Received in revised form: 6 Oktober 2020

Accepted: 10 Desember 2020

Available online: 30 April 2021

licensedbyCreativeCommonsAttribution-ShareAlike4.0InternationalLicense. 


\section{ABSTRACT}

Maternal Mortality Rate (MMR) is an important indicator of public health status. In 2018, district / city data recapitulation shows the number of maternal mortality cases in Kolaka district as many as 7 cases. Based on data obtained at the Kolakaasi Puskesmas in 2018, there were one case of maternal death. Given the occurrence of death in pregnant women, the improvement of communication between health workers and pregnant women must be more effective. This research method is a quantitative study. The research design used was cross sectional, which aims to determine the relationship between the midwives' SMCR communication model and the knowledge of pregnant women in preventing maternal mortality at the Kolakaasi Health Center in 2020. In this study, the sample size was 93 respondents and was carried out on June 25, 2020 at the Kolakaasi Puskesmas. Sampling in this study using probability sampling with simple random sampling technique. Methods of data analysis using the frequency distribution table with the chi square correlation test. After the discovery of the knowledge of pregnant women that is still lacking, it would be better if the midwife's SMCR communication was further improved so that pregnant women could understand the concept of the importance of maintaining the health of pregnant women in preventing maternal deaths. It is hoped that midwives can develop communication in providing information using information media and apply more effective communication skills, and maintain good attitudes of pregnant women in preventing maternal death. From the results of the study it can be concluded that there is a relationship between the SMCR communication model of midwives and the knowledge of pregnant women in preventing maternal mortality.

Keywords: knowledge; communication model; midwife; maternal mortality rate.

\section{PENDAHULUAN}

Angka Kematian Ibu (AKI) menjadi salah satu indikator penting dari derajat kesehatan masyarakat. Angka kematian ibu menggambarkan jumlah wanita yang meninggal dari suatu penyebab kematian terkait dengan gangguan kehamilan atau penanganannya (tidak termasuk kecelakaan atau kasus insidentil) selama kehamilan, melahirkan dan dalam masa nifas (42 hari setelah melahirkan) tanpa memperhitungkan lama kehamilan per 100.000 kelahiran hidup. World Health Organization (WHO) menyatakan bahwa pada tahun 2015 sekitar 830/harinya wanita meninggal di seluruh dunia akibat komplikasi kehamilan dan persalinan, sedangkan secara keseluruhan Angka Kematian Ibu (AKI) sebanyak 303.000/100.000 kelahiran hidup. Hampir semua kematian ibu terjadi di Negara berkembang yaitu lebih dari setengah kematian terjadi di afrika sub-sahara dan hampir di sepertiga terjadi di asia selatan. Ini masih dalam kategori tinggi karena belum mencapai target sustainable development goals (SDG'S) yaitu70 per 100.000 kelahiran hidup.Angka Kematian Ibu (AKI) merupakan salah satu indikator yang peka dalam menggambarkan kesejahteraan masyarakat di Indonesia. Pada tahun 2012 Survei Demografi dan Kesehatan Indonesia (SDKI) menunjukkan peningkatan AKI yang signifikan yaitu menjadi 359 kematian ibu per 100.000 kelahiran hidup. AKI menunjukkan penurunan menjadi 305 kematian ibu per 100.000 kelahiran hidup. ${ }^{1,2,3}$

Berdasarkan hasil Survei Penduduk Antar Sensus (SUPAS) 2015, AKI Indonesia sebesar 305/100.000 kelahiran hidup.Angka tersebut menempatkan Indonesia sebagai negara dengan angka kematian tertinggi kedua di kawasan Asia Tenggara setelah Laos dengan AKI 357 per 100.000. Jika dibandingkan dengan Malaysia dan Singapura, angka tersebut masih sangat tinggi. Pada tahun 2015 Malaysia memiliki angka kematian ibu melahirkan sebesar 24 per 100.000 sementara Singapura hanya 7 per 100.000 kelahiran hidup Tahun 2018 rekapitulasi data kabupaten/kota menunjukkan jumlahkasus kematian ibu di kabupaten kolaka sebanyak 7 kasus.Berdasarkan data yang diperoleh di Puskesmas Kolakaasi pada tahun 2018 terjadi kasus Kematian Ibu berjumlah satu orang. Mengingat terjadinya kematian pada ibu hamil maka peningkatan komunikasi antara petugas kesehatan dengan ibu hamil harus lebih efektif., $4,5,6$

Tingginya angka kematian ibu terkait dengan penyebab langsung yaitu kematian ibu di Indonesia masih didominasi oleh kesehatan ibu saat kehamilan dan persalinan, sedangkan penyebab tidak langsungnya dipengaruhi oleh empat terlalu dan tiga terlambat. Kondisi " $4 \mathrm{~T}$ ” atau biasa yang disebut empat terlalu masih menjadi suatu masalah yang sulit untuk diselesaikan secara tuntas, yaitu terlalu tua untuk hamil, terlalu muda untuk hamil, terlalu banyak jumlah anak, dan terlalu dekat jarak kelahiran kurang dari dua tahun. Dan dipengaruhi oleh tiga terlambat yaitu terlambat mengenali tanda bahaya persalinan dan 
mengambil keputusan, terlambat dirujuk ke fasilitas pelayanan kesehatan, dan terlambat ditangani oleh tenaga kesehatan di fasilitas kesehatan. Selain hal tersebut di atas ibu melahirkan mengalami kematian karena perdarahan, eklamsia, infeksi dan aborsi. Empat faktor ini merupakan 70 persen penyebab yang menimbulkan kematian ibu. ${ }^{7,8,9}$

Upaya untuk mengurangi tingginya tingkat kematian ibu, sesungguhnya tidak cukup hanya dilakukan melalui pendekatan klinis karena persoalannya juga menyangkut aspek non klinis seperti tidak dapat diaksesnya fasilitas perawatan kesehatan yang berkualitas, kurangnya perawat kesehatan yang terlatih, kurangnya pengetahuan dan kesadaran akan kecepatan terkait masalah kesehatan ibu, status kesehatan rendah dan tingkat anal gizi dan wanita hamil, penggunaan kontrasepsi tingkat rendah dan tingkat kesulitan yang belum terpenuhi, serta pengukuran Rasio Kematian Ibu yang tidak akurat.Petugas kesehatan yang berhubungan dengan klien atau pasien diharuskan memiliki keterampilan komunikasi yang baik, salah satunya adalah berkomunikasi dengan klien/pasien secara langsung atau saling berhadap-hadapan (face to face) dan petugas kesehatan juga di haruskan sering senyum agar klien atau pasien tidak merasa bosan saat memeriksakan kesehatannya ${ }^{7,8,9}$

Model komunikasi SMCR terdiri dari 4 variabel, yakni sumber, pesan, saluran, dan penerima. Salah satu kekuatan dari model ini adalah bahwa komunikasi dilihat sebagai suatu proses yang dinamis, bukan sekadar peristiwa yang statis.Bidan yang berhubungan dengan klien atau pasien diharuskan memiliki keterampilan komunikasi yang baik. Dalam berkomunikasi pada umumnya berjalan dengan lancar dan masing-masing pihak saling memahami pesan yang mereka sampaikan. Namun demikian adakalanya proses komunkasi tersebut mengalami suatu pergangguan dan masing-masing pihak mengalami kesalahfahaman. Demikian juga komunikasi yang kurang lancar terjadi dalam rangka pelayanan medis. Pada dasarnya komunikasi yang terbentuk dalam pelayanan medis adalah komunikasi antar pribadi, tetapi terkadang petugas kesehatan tidak menyadari bahwa pesan yang mereka sampaikan kepada pasien pada saat memberikan pelayanan tidak dapat sepenuhnya diterima dengan baik oleh pasien, karena aspek psikologis yang menjadi pertimbangan, sehingga cara komunikasi yang mereka gunakan kadang-kadang kurang efektif . ${ }^{10}$

\section{METODE}

Penelitian ini merupakan penelitian kuantitatif. Desain penelitian yang digunakan yaitu cross sectional yang bertujuan untuk mengetahui hubungan model komunikasi SMCR bidan dengan perilaku ibu hamil dalam mecegah kematian ibu. Penelitian ini dilaksanakan di Puskesmas Kolakaasi Kec. Latambaga Kabupaten Kolaka dilakukan pada tanggal 29 Juni - 13 Juli tahun 2020 dengan populasi rata-rata kunjungan ibu hamil perbulan di Puskesmas Kolakaasi Kec. Latambaga Kabupaten Kolaka. Sampel dalam penelitian ini adalah ibu hamil yang bertempat diwilayah kerja Puskesmas Kolakaasi Kec. Latambaga Kabupaten Kolaka berjumlah 93 ibu hamil.

Analisis data yang dilakukan adalah univariat dan bivariat dengan uji chi-square, penyajian data disajikan dalam bentuk tabel dan narasi.Data primer diperoleh dari responden dengan melakukan wawancara secara langsung menggunakan daftar pertanyaan (kuesioner). Data sekunder dalah data yang secara tidak langsung diperoleh dari sumbernya. Pengolahan data dilakukan dengan cara komputerisasi dengan menggunakan SPSS. Analisis data dilakukan dengan analisis univariat dilakukan dengan cara mendeskripsikan tiap veriabel penelitian untuk mendapatkan gambaran umum dengan melihat distribusi frekuensi dari variable penelitian dalam bentuk tabel distribusi frekuensi dan narasi. Analisis bivariat bertujuan untuk mengetahui hubungan antara variabel bebas dengan variabel terikat dengan menggunakan uji chi square dengan tingkat kesalahan $\alpha=0,05$.

\section{HASIL}


Berdasarkan tabel 1 diperoleh ibu hamil yang berumur $<21$ tahun sebanyak 6 responden $(6,5 \%), 21$ - 35 tahun sebanyak 67 responden (72.0\%), dan >35 tahun sebanyak 20 responden (21.5\%). Pada tabel 2, terlihat bahwa probabilitas Chi-squar 0,003 <0,05 yang mengartikan ada hubungan antara model komunikasi bidan SMCR dengan pengetahuan ibu hamil.

Tabel 1.Distribusi Karakteristik Responden

\begin{tabular}{|c|c|c|}
\hline Profil & $\mathrm{n}$ & $\%$ \\
\hline \multicolumn{3}{|l|}{ Kelompok Umur } \\
\hline$<21$ tahun & 6 & 6,5 \\
\hline $21-35$ tahun & 67 & 72,0 \\
\hline$>35$ tahun & 20 & 21.5 \\
\hline \multicolumn{3}{|l|}{ Pendidikan } \\
\hline Tidak pernah sekolah & 3 & 3.2 \\
\hline SD & 14 & 15.1 \\
\hline SMP & 25 & 26.9 \\
\hline SMA & 39 & 41.9 \\
\hline D3 & 9 & 9.7 \\
\hline $\mathrm{S} 1$ & 3 & 3.2 \\
\hline \multicolumn{3}{|l|}{ Pekerjaan } \\
\hline PNS & 15 & 16.1 \\
\hline Pedagang / Wiraswasta & 18 & 19.4 \\
\hline Petani & 8 & 8.6 \\
\hline Ibu Rumah Tangga & 41 & 44.1 \\
\hline Lainnya & 11 & 11.8 \\
\hline \multicolumn{3}{|l|}{ Kehamilan } \\
\hline 1 & 22 & 23.6 \\
\hline $2-3$ & 46 & 49.5 \\
\hline$>3$ & 28 & 27,3 \\
\hline \multicolumn{3}{|l|}{ Umur Kehamilan } \\
\hline Trimester 1 & 16 & 17.2 \\
\hline Trimester 2 & 34 & 36.5 \\
\hline Trimester 3 & 43 & 46.2 \\
\hline \multicolumn{3}{|l|}{ Kategori Tekanan Darah } \\
\hline Tidak Normal & 3 & 3.2 \\
\hline Normal & 90 & 96.8 \\
\hline \multicolumn{3}{|l|}{ LILA } \\
\hline$<23.5$ & 14 & 15.1 \\
\hline$\geq 23,5$ & 79 & 84.9 \\
\hline
\end{tabular}

Tabel 2.Distribusi Responden Berdasarkan Hubungan Model Komunikasi SMCR Bidan dengan Pengetahuan Ibu hamil

\begin{tabular}{|c|c|c|c|c|c|c|c|c|}
\hline \multirow{3}{*}{ Model Komunikasi } & \multirow{3}{*}{ SMCR Bidan } & \multicolumn{4}{|c|}{ Pengetahuan } & \multirow{2}{*}{\multicolumn{2}{|c|}{ Total }} & \multirow{3}{*}{$\begin{array}{c}P \\
\text { Value }\end{array}$} \\
\hline & & \multicolumn{2}{|c|}{ Kurang } & \multicolumn{2}{|c|}{ Cukup } & & & \\
\hline & & $\mathrm{n}$ & $\%$ & $\mathrm{~N}$ & $\%$ & $\mathrm{n}$ & $\%$ & \\
\hline Kurang & & 8 & 22.9 & 27 & 77.1 & 35 & 37.1 & \multirow{3}{*}{0,003} \\
\hline Baik & & 2 & 3,4 & 56 & 96.6 & 58 & 62.3 & \\
\hline Total & & 10 & 26.3 & 83 & 173,7 & 93 & 100,0 & \\
\hline
\end{tabular}


Pengetahuan merupakan hasil dari tahu, dan ini terjadi setelah orang melakukan penginderaan terhadap suatu obyek tertentu. Penginderaan terjadi melalui panca indera manusia, yakni indera penglihatan, pendengaran, penciuman, rasa, dan raba. Sebagian besar pengetahuan manusia diperoleh melalui mata dan telinga. ${ }^{11,12,13}$

Hubungan model komunikasi bidan dengan ibu hamil terjalin apabila komunikasi yang dilakukan dapat memberikan pengaruh terhadap ibu hamil. Peningkatan pengetahuan kesehatan akan menentukan ibu hamil untuk berperilaku baik dalam memelihara kesehatan dan mencegah kematian ibu . upaya yang dilakukan untuk meningkatkan pengetahuan ibu hamil yang dilakukan bidan adalah antara lain dengan penyebar luasan informasi kesehatan salah satunya mencegah kematian ibu. Oleh karena itu pengetahuan ibu hamil dapat bertambah dengan cara menerima informasi dari bidan. ${ }^{14,15,16}$

Dalam penelitian ini yang mengartikan bahwa ada hubungan antara model komunikasi SMCR dengan pengetahuan ibu hamil, hal ini dapat dilihat dari kurangnya pengetahuan ibu hamil tentang pengertian kematian ibu serta cara mencegah kematian ibu , maka dari itu dengan penelitian ini diharapkan bidan lebih meningkatkan komunikasi kepada ibu hamil dengan pemberian informasi menggunakan media informasi untuk menambah pengetahuan ibu hamil tentang bagaimana agar tetap menjaga kesehatan ibu hamil khususnya masalah mencegah kematian ibu , bukan hanya pemberian informasi secara langsung yang diberikan tetapi informasi bisa didapatkan dari media yang diberikan serta perlunya bidan berkomunikasi dengan baik pada ibu hamil, cara bidan berkomunikasi dengan ibu menentukan informasi apa dan berapa banyak pengetahuan yang didapat ibu hamil dari bidan tersebut.

Peningkatan pengetahuan kesehatan akan menentukan ibu hamil untuk berperilaku baik dalam memelihara kesehatan dan mencegah kematian ibu. ${ }^{17,18,19}$ Upaya yang dilakukan untuk meningkatkan pengetahuan ibu hamil yang dilakukan bidan adalah antara lain dengan penyebar luasan informasi kesehatan salah satunya mencegah kematian ibu. Oleh karena itu pengetahuan ibu hamil dapat bertambah dengan cara menerima informasi dari bidan. Pengetahuan yang kurang tentang upaya pencegahan kematian ibu dapat menimbulkan sikap dan tindakan yang kurang dalam pelaksanaan yang berdampak pada ketidak optimalan dalam mencegah terjadinya kematian ibu selama kehamilan . Dari Hasil observasi beberapa jawaban pertanyaan ibu hamil tentang pengetahuan cukup masih didapati kurang sebanyak 35 (37.6\%) responden karena pengetahuan tentang pengertian kematian ibu didapati sebanyak 60 (64.5\%), pengetahuan tentang penyebab kematian ibu didapati sebanyak 58 (62.4\%) ibu mengkonsumsi gizi seimbang setiap hari didapati sebanyak 71 (76.3\%). Berdasarkan Hasil observasi yang dilakukan tentu sangat penting dalam meningkatkan pengetahuan ibu hamil dan ditunjang dengan penerimaan informasiinformasi dari bidan khususnya terkait masalah pencegahan kematian ibu.

Hal ini sejalan dengan penelitian yang dilakukan Dinda Permatasari (2016) dimana hasil penelitiannya menunujukkan bahwa ada hubungan yang signifikan antara komunikasi dengan pengetahuan. ${ }^{11}$ Hal ini memperkuat dengan teori Green bahwa pengetahuan merupakan faktor yang mempermudah terjadinya suatu perilaku. ${ }^{20,21}$

Dalam penelitian ini yang mengartikan bahwa ada hubungan antara model komunikasi SMCR dengan pengetahuan ibu hamil_ hal_ini_dapat dilihat dari_kurangnya pengetahuan ibu_hamil_tentang 
pengertian kematian ibu serta cara mencegah kematian ibu , maka dari itu dengan penelitian ini diharapkan bidan lebih meningkatkan komunikasi kepada ibu hamil dengan pemberian informasi menggunakan media informasi untuk menambah pengetahuan ibu hamil tentang bagaimana agar tetap menjaga kesehatan ibu hamil khususnya masalah mencegah kematian ibu , bukan hanya pemberian informasi secara langsung yang diberikan tetapi informasi bisa didapatkan dari media yang diberikan serta perlunya bidan berkomunikasi dengan baik pada ibu hamil, cara bidan berkomunikasi dengan ibu menentukan informasi apa dan berapa banyak pengetahuan yang didapat ibu hamil dari bidan tersebut.Hal ini sejalan dengan penelitian yang dilakukan Dinda Permatasari dengan nilai $p$ (value) $=0,048$ dimana hasil penelitiannya menunujukkan bahwa ada hubungan yang signifikan antara komunikasi dengan pengetahuan. ${ }^{11} \mathrm{Hal}$ ini memperkuat dengan teori Green bahwa pengetahuan merupakan faktor yang mempermudah terjadinya suatu perilaku. ${ }^{12,21}$

\section{KESIMPULAN DAN SARAN}

Berdasarkan hasil penelitian mengenai Hubungan Komunikasi SMCR Bidan dengan Perilaku Ibu hamil dalam Mencegah Kematian Ibu di Puskesmas Kolakaasi Tahun 2020, maka dapat disimpulkan bahwa Ada hubungan antara model komunikasi bidan dengan pengetahuan ibu hamil di Puskesmas Kolakaasi tahun 2020 dengan nilai $\mathrm{p}$ (value) = 0,003 yang berarti lebih kecil dari 0,05. Diharapkan komunikasi SMCR bidan lebih ditingkatkan lagi dengan melakukan pendekatan baik penyampaian pesan, materi yang mudah di pahami, maupum keterbukaan agar ibu hamil semakin paham dengan konsep pentingnya menjaga kesehatan ibu hamil dalam mencegah kematian ibu tersebut. Diharapkan bidan dapat mengembangkan komunikasi dalam memberikan informasi menggunakan media informasi dan menerapakan keterampilankomunikasi yang lebih efektif.

\section{DAFTAR PUSTAKA}

1. Yuwindi. Peran Tokoh Masyarakat Sebagai Determinan Utama dari Komitmen Kader dalam Program Perencanaan Persalinan dan Pencegahan Komplikasi The Role of Community Leaders as the Key Determinants Against The Commitment of Cadres in the Implementation of Birth Planning. 2017. $5(2), 1-8$.

2. Kemenkes RI. Situasi Kesehatan Ibu.Infodatin, Jakarta : Kementerian Kesehatan Republik Indonesia. 2014

3. Dwijayanti, K. Indeks Prediktif Risiko Kematian Ibu Di Kota Surabaya. Tesis Program studi Epidemiologi. Universitas Airlangga. 2016

4. Profil Kesehatan Puskesmas Kolakaasi Data dan Informasi Dinas Kesehatan Kabupaten Kolaka Puskesmas Kolakaasi. 2019

5. Chasanah. Peran Petugas Kesehatan Masyarakat Dalam Upaya Penurunan Angka Kematian Ibu Pasca Mdgs 2015. Jurnal Kesehatan Masyarakat Andalas. 2017. Vol. 9. No. 2

6. Sumardiyono. Pencegahan Kematian Ibu dan Anak melalui Pendekatan Strategi Komunikasi pada Program Emas Expanding Maternal and Neonatal Survival.Jurnal Ilmu Komunikasi. 2016. Vol. 14 No.3 
7. Febrianto. Komunikasi Dokter dan Pasien di Poly Anak Rumah Sakit. Universitas Muhammadiyah Malang. 2018

8. Sumardiyono. Pencegahan Kematian Ibu dan Anak melalui Pendekatan Strategi Komunikasi pada Program Emas Expanding Maternal and Neonatal Survival. Jurnal Ilmu Komunikasi. 2016. Vol. 14 No.3

9. Wijaya. Efektivitas Komunikasi Interpersonal Terhadap Pelayanan Kesehatan Di Rsud Syekh Yusuf Kabupaten Gowa. Skripsi Jurusan Ilmu Komunikasi Pada Fakultas Dakwah dan Komunikasi UIN Alauddin Makassar. 2015

10. Notoadmodjo. Promosi Kesehatan, Teori dan aplikasi, Jakarta, Rineka cipta. 2005

11. Dinda Permatasari. Faktor - Faktor Yang Berhubungan Dengan Komunikasi Terapeutik Bidan Puskesmas Dalam Memberikan Pelayanan Kesehatan Di Puskesmas Kota Semarang. Jurnal Kesehatan Masyarakat. 2016. Vol. 4. No. 2.

12. Lawrence W.Green \& Marshall W. Kreuter. Health Promotion Planning: an Educational and Environmental Approach Second Edition. Mayfield Publishing Company. California. 2000

13. Agatha Maria. Sikap Dan Komunikasi Bidan Terhadap Tingkat Kepuasan Ibu Hamil Pada Pelaksanaan Antenatal Care. Jurnal vokasi Kesehatan. 2015. Vol. 1. No. 5

14. Notoadmojo. Promosi Kesehatan \& Ilmu Perilaku.J akarta : Rineka Cipta. 2007

15. Prasetyaningsih A, Sudargo T, Susilo J. Pengetahuan, Sikap Dan Ketrampilan. 2005

16. Penjamah Makanan Yang Diberi Pelatihan Keamanan Pangan di Instalasi Gizi RS Jantung harapan Kita. Jurnal Gizi Klinik Indonesia; 2018. 2 (2): 71

17. Yusriani Y, Alwi MK. Buku ajar promosi kesehatan dan pemberdayaan masyarakat. Book \& Articles Of Forikes. 2018 Mar 31;9:1-59.

18. Dewi, S.; Romalita, Y.; Yusriani, Y.; Alwi, M. Perceptions of Pregnant Woman on Monetary and Time Sacrifice for Satisfaction Based on Health Workers Roles in Antenatal Services to Reduce the Risk of Maternal Death at Gowa District. hsji 2019, 10, 111-118.

19. Alwi MK, Nugroho HS. The effect of training on efforts to reduce maternal mortality risk to behavior of community-based safe motherhood promoters (SMPs). Indian Journal of Public Health Research \& Development. 2018;9(11):339-45.

20. Yusriani Y, Alwi MK. Implementasi pelayanan kesehatan ibu di wilayah kerja Puskesmas Bontomate'ne, Kecamatan Turatea, Kabupaten Jeneponto. InProsiding Seminar Nasional Sinergitas Multidisiplin Ilmu Pengetahuan dan Teknologi 2018 Jul 31 (Vol. 1, pp. 157-163).

21. Mardha MS, Panjaitan IS. Pengetahuan Dan Sikap Ibu Dengan Keikutsertaan Dalam Kelas Senam Hamil Di Rumah Sakit Colombia Asia. Window of Health: Jurnal Kesehatan. 2020 Apr 25:168-75. 